\title{
A trio of multiple Wilms' tumours
}

S. Andronikou FC Rad Diag (SA)

C. Welman E. Kader

Department of Paediatric Radiology, University of Cape Town and Institute of Child Health, Red Cross War Memorial Children's Hospital,

Rondebosch, Cape Town

Corresponding author S. Andronikou

Department of Paediatric Radiology Red Cross War Memorial Children's Hospital Cape Town
7700

Telephone: 021-6585442

Fax: 021-6585101

E-mail: docsav@mweb.co.za

\section{Abstract}

Wilms' tumour is the commonest malignant abdominal tumour in children. Unilateral multicentric, and bilateral Wilms' tumours are, however, less common, occurring in $7 \%$ and $5 \%$ of cases respectively. These are often associated with sporadic aniridia, genitourinary anomalies, hemihypertrophy and nephroblastomatosis. Nephroblastomatosis is a separate entity that may act as a precursor of Wilms' tumours. We present three cases of multiple Wilms'

tumours. Two cases also had

nephroblastomatosis which was not seen on pre-operative CT imaging but was identified in one case at MRI. In cases of multiple Wilms' tumours, MRI provides better delineation of the tumours and may, therefore, affect management.

\section{Key words}

Wilms' tumour, nephroblastomatosis, magnetic resonance imaging (MRI), computed tomography (CT), horseshoe kidney.

\section{Introduction}

Wilms' tumour (WT) is the commonest malignant abdominal tumour in children.' Unilateral multicentric, and bilateral WT are less common. We present three cases of multiple WT and their imaging features.

\section{Case 1}

A 2-year-old boy presented with a month's history of weight loss and a palpable right-sided abdominal mass. Ultrasound (US) and computed tomography (CT) showed large upper pole and smaller lower pole masses in the right kidney (Figures la and $\mathrm{b}$ ). A right nephrectomy was performed and histology demonstrated nephroblastomatosis and three WT of favourable histology.

\section{Case 2}

A 4-year-old boy with multiple congenital anomalies, including a horseshoe kidney, presented with macroscopic haematuria. A palpable abdominal mass was sonographically shown to arise from the left side of the horseshoe kidney. On CT, bilateral renal masses were seen in keeping with WT (Figures 2a and b). In 


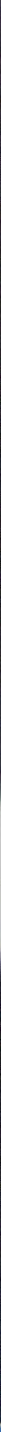

lopromide

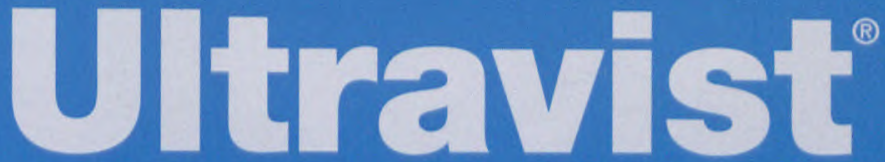

Ultravist fulfils all requirements

for a modern diagnostic agent:

non-ionic

a monomeric

口 low-osmolar

a well tolerated

a low viscosity 


\section{from page 4}

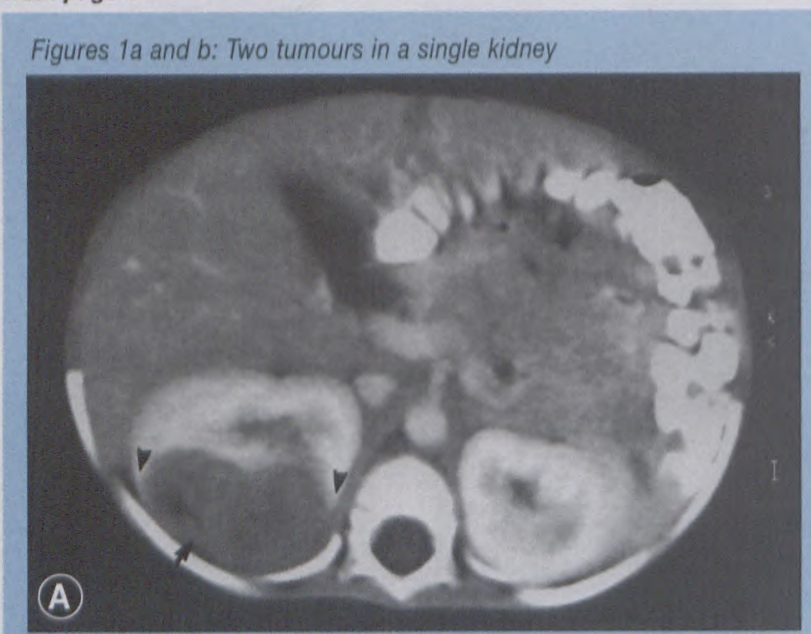

a. Post-contrast CT shows a low density mass (arrow) in the posterolateral upper pole of the right kidney with a typical claw sign (arrowheads).

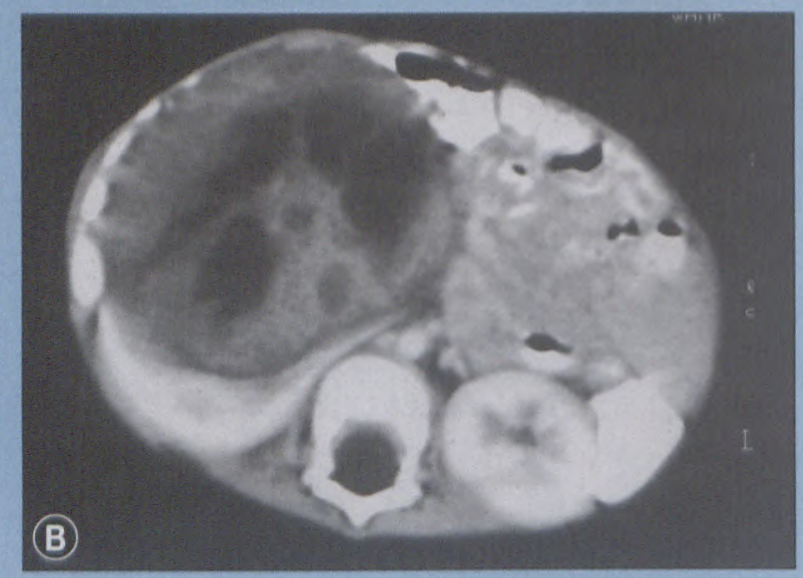

b. Post-contrast CT of the same patient shows another mass with cystic components in the anteromedial lower pole of the right kidney.

view of the clinical setting, the child was managed conservatively until his death.

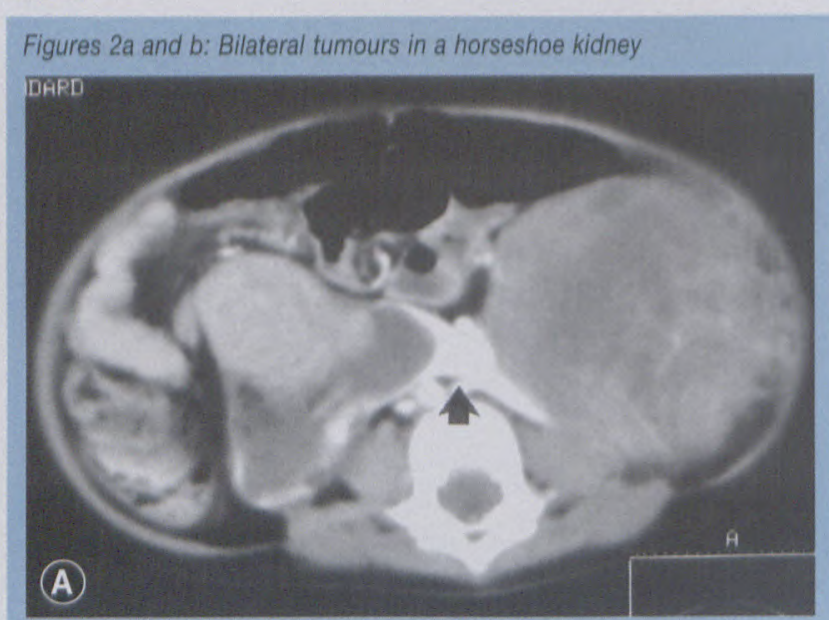

a. Post-contrast CT shows masses in both kidneys with a contrastenhancing isthmus (arrow) of the horseshoe kidney.

\section{Case 3}

A 4-yearold boy presented with a 10-day history of anorexia, abdominal pain and intermittent fever. An US and CT scan (Figure 3a) demon-

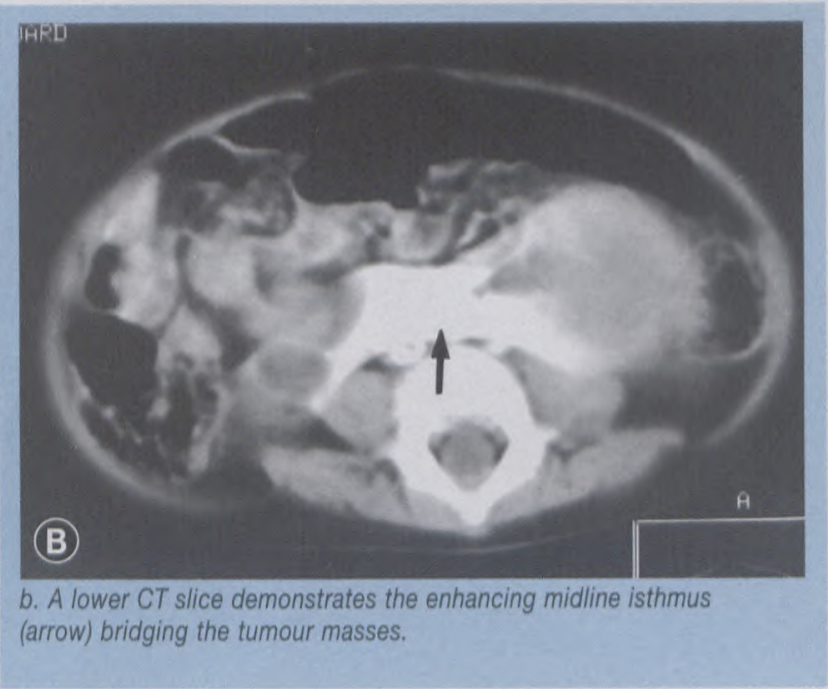
strated bilat-

eral renal masses (two in the right kidney and one on the left). After chemotherapy, the left WT was removed by partial nephrectomy. A DMSA scan demonstrated a differential function of $68 \%$ on the right and $32 \%$ on the left. Repeat CT showed more than one mass in the right kidney. In view of possible salvage surgery in the better functioning right kidney, an MRI was performed to delineate the extent of the masses. At least five masses were demonstrated (Figures $3 b, c, d$ ), three of which were histologically proven nephroblastomatosis. A repeat course of chemotherapy was instituted.

\section{Discussion}

Wilms' tumour is the commonest malignant abdominal tu- mour of children between one and eight years of age and is the third commonest cause for a renal mass in childhood after hydronephrosis and multicystic dysplastic kidney. ${ }^{1}$ The commonest presentation is with an asymptomatic abdominal mass. Uncommon presentations include abdominal pain, fever, anorexia, haematuria and hypertension. Although mostly sporadic, WT are associated with several conditions, including horseshoe kidneys, BeckwithWiedemann syndrome and sporadic aniridia. ${ }^{2}$ Bilateral tumours occur in $5 \%$ of cases and unilateral multicentric tumours in $7 \%$. Bilateral tumours are often associated with sporadic aniridia, genitourinary anomalies, hemihypertrophy and nephroblastomatosis (persistent metanephric blastemal rests found after 34 weeks' gestation). Nephroblastomatosis is considered an intermediate between a malformation and neoplasm. . $^{3,4}$ These nephrogenic rests are seen in $1 \%$ of autopsies of children under three months of age. ${ }^{2}$ They are associated with synchronous bilateral WT in $99 \%$, and with metachronous bilateral WT in $94 \%$ of cases. Nephroblastomatosis therefore has 


\section{from page 6}

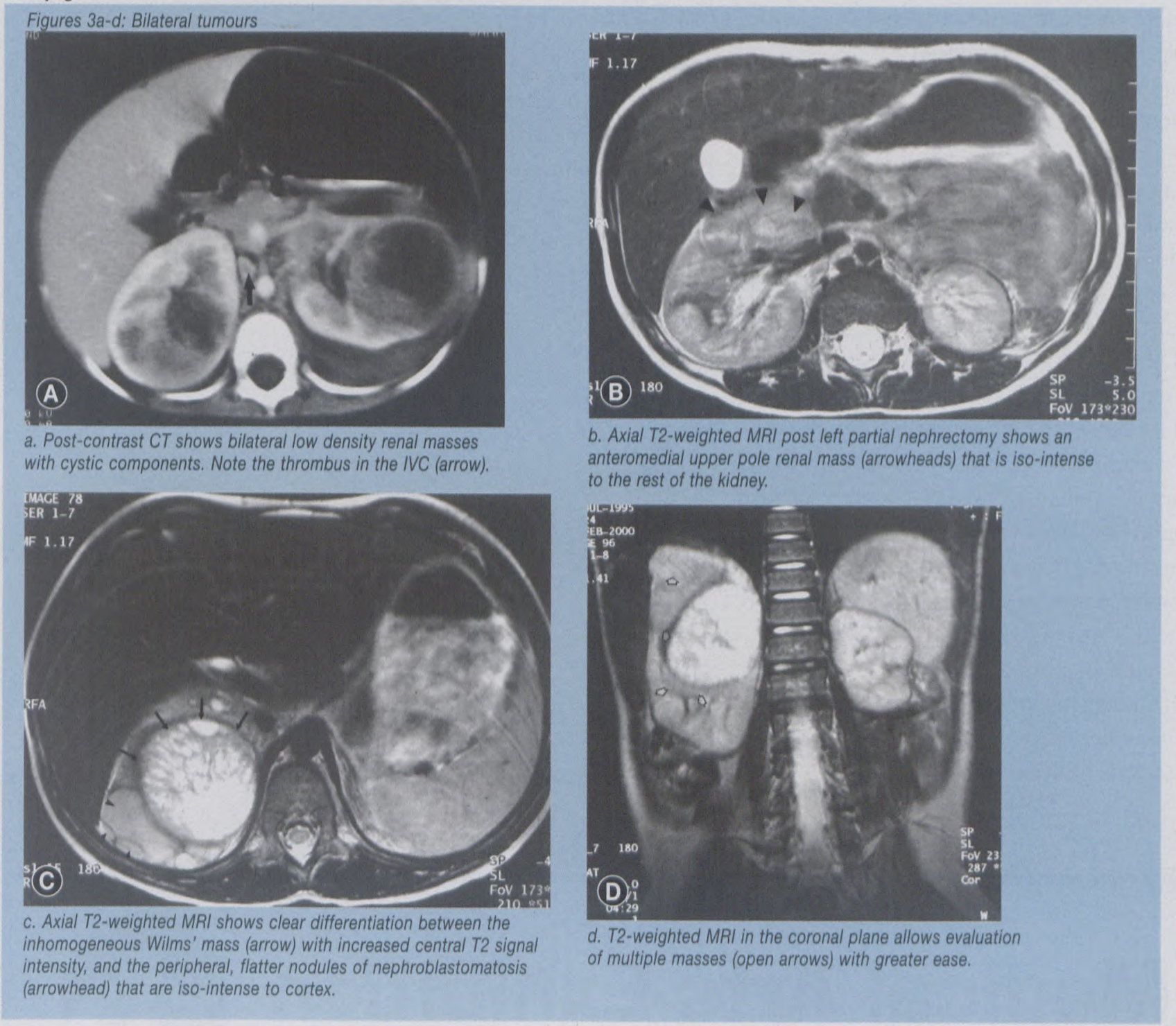

malignant potential and is hence a precursor of WT. ${ }^{3}$ While ultrasound is often the initial investigation and provides good detail of IVC tumour thrombus, CT scanning provides better detail of the tumours. Post-treatment imaging is necessary to detect recurrence and metachronous tumours - especially with associations known to develop multiple WT. ${ }^{2}$ On $\mathrm{CT}$, the tumour is typically of inhomogeneous low-density with increased inhomogeneity post-contrast. A 'claw sign' confirms the renal origin of the mass. The mass is usually solid but haemorrhage and necrosis may cause cystic areas. Calcification is seen in up to $15 \%$ of cases. MRI is helpful in difficult cases as coronal imaging allows better tumour delineation. Generally WT are heterogeneous with low signal intensity on T1weighting, high signal on $\mathrm{T} 2$-weighting and show inhomogeneous contrast enhancement. Haemorrhage and necrosis may alter these appearances. ${ }^{3}$ Differential diagnosis includes neuroblastoma, nephroblastomatosis, mesoblastic nephroma, multilocular cystic renal tumours, renal cell carcinoma, renal lymphoma, renal leukaemia, clear-cell sarcoma and rhabdoid tumours of the kidney. Nephrogenic rests may either be perilobar (periph- eral) or intralobar (central). The intralobar rests are associated with more frequent development of WT and at a younger age. ${ }^{4} \mathrm{On} \mathrm{CT}$, the nephrogenic rests are typically well-defined plaque-like or nodular subcapsular masses that are homogenously isodense to renal cortex. They enhance poorly and hence appear hypo-dense relative to renal cortex. On MRI they are iso- to hypo-intense to renal cortex on both T1- and T2-weighted sequences. They enhance poorly with gadolinium and are hypo-intense relative to renal cortex. Both nephroblastomatosis and WT are best seen on post-gadolinium images. The 


\section{A trio of multiple Wilms' tumours}

\section{from page 7}

most reliable differentiation between them is based on their homogeneity. ${ }^{3}$ In practice, the imaging ${ }^{4}$ and surgery ${ }^{5}$ for WT often differs from the National Wilms' Tumour Study Group (NWTSG) protocol. Controversial points include radiological or surgical staging, timing of chemotherapy, the adequacy of partial nephrectomy, and the optimum follow-up surveillance, ${ }^{4,5}$ This is especially so for multiple WT where the surgical approach and need for accurate follow-up surveillance is complicated by the presence of multiple potentially malignant nephrogenic rests. Cases one and three had nephroblastomatosis which was not seen on pre-operative $\mathrm{CT}$ imaging. In case three it was, however, identified on the pre-operative MRI scan. In view of these problems, it may be advisable to consider MRI in complicated cases with multiple WT.

\section{Conclusion}

In cases of multiple WT, MRI provides better delineation of the tumours and increased sensitivity for detecting nephroblastomatosis. It should be considered in the tumour work-up as it may affect management.

\section{References}

1. Chapman S, Nakielny R. Aids to radiological differential diagnosis. 3rd ed. London: WB Sanders. 1995:309-310, 317 .

2. Barnewolt CE, Paltiel HJ, Lebowitz RL Kirks DR. Genitourinary tract. In: Kirks DR \& Griscom NT, eds. Practical paediatric imaging. 3rd ed. Philadelphia: LippincottRaven. 1998:1111-1126.

3. Rohrschneider WK, Weirich A, Rieden K Darge K, Tröger J, Graf N. US, CT and MR imaging characteristics of nephroblastomatosis. Paediatr Radiol, 1998 ; 28:435-443

4. Goske MJ, Mitchell C, Reslan WA. Imaging of patients with Wilms' tumour. Sem Urol Oncol 1999; 17:11-20.

5. Ross JH, Kay R. Surgical considerations for patients with Wilms' tumour. Sem Uro Oncol 1999; 17:33-39.

\section{Medical Arts Exhibition 2000}

Dates: $\quad 28^{\text {th }}$ August $-3^{\text {rd }}$ September 2000

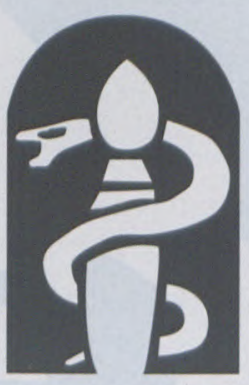

Venue: Pharmaceutical Society of South Africa

52 Glenhove Street, Houghton

Viewing: $\quad$ 08:00 - 17:00 weekdays

09:00 - 12:00 Saturday

For more information or if you are interested in exhibiting, please contact Heide Deane at (011) 463-4100 